\title{
Pensamento Lean e cuidado do paciente em morte encefálica no processo de doação de órgãos
}

\author{
LEAN THINKING AND BRAIN-DEAD PATIENT ASSISTANCE IN THE ORGAN DONATION \\ PROCESS
}

\section{PENSAMIENTO LEAN Y CUIDADO DEL PACIENTE CON MUERTE ENCEFÁLICA EN EL PROCESO DE DONACIÓN DE ÓRGANOS}

\section{Aline Lima Pestana ${ }^{1}$, José Luís Guedes dos Santos², Rolf Hermann Erdmann³, Elza Lima da Silva ${ }^{4}$, Alacoque Lorenzini Erdmann ${ }^{5}$}

\section{RESUMO}

A doação de órgãos é um processo complexo que desafia os profissionais e gestores do sistema de saúde. Este estudo objetiva apresentar um modelo teórico de organização do cuidado ao paciente em morte encefálica e o processo de doação de órgãos, balizado pelas principais ideias do pensamento Lean que possibilitam a melhoria da produção a partir de ciclos de planejamentos e criação de um ambiente propício para o sucesso da sua implementação. 0 pensamento Lean pode tornar mais eficaz e eficiente o processo de doação de órgãos e contribuir com a sua melhoria, a partir da sistematização das informações e capacitação dos profissionais para a excelência do cuidado. $O$ modelo apresentado configura-se como um referencial disponível para validação e aplicação pelos profissionais e gestores de saúde e enfermagem na prática da gestão do cuidado ao paciente potencial doador de órgãos em morte encefálica e respectiva demanda por transplante.

\section{DESCRITORES}

Morte encefálica

Doadores de órgãos

Administração dos cuidados ao paciente

Cuidados de enfermagem

Gestão de qualidade

\begin{abstract}
Organ donation is a complex process that challenges health system professionals and managers. This study aimed to introduce a theoretical model to organize brain-dead patient assistance and the organ donation process guided by the main lean thinking ideas, which enable production improvement through planning cycles and the development of a proper environment for successful implementation. Lean thinking may make the process of organ donation more effective and efficient and may contribute to improvements in information systematization and professional qualifications for excellence of assistance. The model is configured as a reference that is available for validation and implementation by health and nursing professionals and managers in the management of potential organ donors after brain death assistance and subsequent transplantation demands.
\end{abstract}

\author{
DESCRIPTORS \\ Brain death \\ Organ donors \\ Patient assistance management \\ Nursing assistance \\ Quality management
}

\begin{abstract}
RESUMEN
\author{
DESCRIPTORES \\ Muerte encefálica \\ Donadores de tejido \\ Manejo de atención al paciente \\ Atención de enfermería \\ Gestión de calidad
}

La donación de órganos es un proceso complejo que desafía a profesionales y gerenciadores del sistema de salud. Se objetiva presentar un modelo teórico de organización del cuidado al paciente con muerte encefálica y el proceso de donación de órganos, orientado por las principales ideas del pensamiento Lean que posibilitan la mejora de producción mediante ciclos de planificación y creación de ambiente propicio para el éxito en su implementación. El pensamiento Lean puede mejorar eficacia y eficiencia del proceso de donación de órganos y contribuir a su mejora, a partir de la sistematización de informaciones y capacitación de los profesionales para la excelencia del cuidado. El modelo presentado configura un referencial disponible para validación y aplicación por parte de profesionales y administradores de salud y enfermería en la práctica de la gestión de cuidado al paciente potencial donante de órganos con muerte encefálica y las respectivas solicitudes de transplantes.

\footnotetext{
${ }^{1}$ Enfermeira. Mestranda em Enfermagem pelo Programa de Pós-Graduação em Enfermagem da Universidade Federal de Santa Catarina. Bolsista CNPq. Integrante do Grupo de Estudos e Pesquisas em Administração, Gerência do Cuidado e Gestão Educacional em Enfermagem e Saúde - GEPADES. Florianópolis, SC, Brasil. aline_lima_pestana@yahoo.com.br ${ }^{2}$ Enfermeiro. Doutorando em Enfermagem pelo Programa de Pós-Graduação em Enfermagem da Universidade Federal de Santa Catarina. Bolsista CAPES. Integrante do GEPADES. Florianópolis, SC, Brasil. joseenfermagem@gmail.com ${ }^{3}$ Doutor em Engenharia da Produção. Professor Associado do Departamento de Administração da Universidade Federal de Santa Catarina. PQDT2 do CNPq. Florianópolis, SC, Brasil. erdmann@newsite.com.br ${ }^{4}$ Enfermeira. Doutoranda do Programa de Pós Graduação do DINTER da Universidade Estadual do Rio de Janeiro. Professora Adjunta do Departamento de Enfermagem da Universidade Federal do Maranhão. São Luís, MA, Brasil. elza.lima@terra.com.br ${ }^{5}$ Doutora em Filosofia da Enfermagem. Professora Titular do Departamento de Enfermagem. Programa de Pós- Graduação em Enfermagem da Universidade Federal de Santa Catarina. Pesquisadora 1A do CNPq. Líder do GEPADES. Florianópolis, SC, Brasil. alacoque@newsite.com.br
}

$\begin{aligned} \text { Rev Esc Enferm USP } & \text { Recebido: 10/05/2012 } \\ \text { 2013; 47(1):258-64 } & \text { Aprovado: 11/07/2012 }\end{aligned}$




\section{INTRODUÇÃO}

O transplante de órgãos é um processo que inicia com a doação de um órgão. Trata-se de uma alternativa terapêutica segura e eficaz no tratamento de diversas doenças que causam insuficiências ou falências de alguns órgãos ou tecidos, tais como insuficiência renal ou cardíaca, determinando melhoria na qualidade e na perspectiva de vida das pessoas acometidas por tais doenças. Constitui-se na retirada de órgãos viáveis de corpos humanos de doador cadáver ou de doador vivo. No caso, dos indivíduos em morte encefálica (doador cadáver), seus órgãos substituirão os órgãos ineficientes de outra pessoa (receptor). O processo de doação de órgãos é complexo, e compreende um conjunto de ações e procedimentos que consegue transformar um potencial doador em um doador efetivo ${ }^{(1-2)}$.

Esse processo de transformação de potencial doador em doador efetivo geralmente se desenvolve numa Unidade de Terapia Intensiva (UTI) ou em Serviços de Emergência, e exige que a equipe multiprofissional seja qualificada e preparada para lidar com essa situação tanto na dimensão técnico-científica quanto humanística, que são inerentes ao cuidado de enfermagem. O reconhecimento tardio da morte encefálica pode acarretar em infecção, instabilidade hemodinâmica ou parada cardiorrespiratória, acarretando na perda do potencial doador, e, consequentemente na perda da esperança de levar vida a outros pacientes.

O cuidado de um paciente em morte encefálica é vivenciado por enfermeiros como uma situação desafiadora do ponto de vista ético e profissional, pois requer ações que exigem grande responsabilidade onde nada pode dar errado no que se refere ao encontro com a família e em termos de conhecimento e cuidado com o potencial doador ${ }^{(3)}$. Os familiares que vivenciam o processo de doação, por sua vez, sofrem ao receber a notícia da morte encefálica, com a falta de informações e demora na liberação do corpo, o que acena para necessidade dos profissionais de saúde prestarem maior atenção à família e pensarem em estratégias para tornar esse processo menos sofrido, burocrático, desgastante e cansativo ${ }^{(4)}$.

Com base no exposto, e diante dos inúmeros cuidados (ou falta deles) capazes de inviabilizarem um processo de doação, surgiu o interesse de correlacionar o pensamento Lean ou produção enxuta a esse processo de doação de órgãos e suas implicações no cuidado ao paciente em morte encefálica. Partiu-se do pressuposto de que, sendo a doação de órgãos passível de interpretação como um sistema de produção, caberia associar as ideias vigentes relacionadas a este último, na direção de busca da qualidade, eficiência e eficácia na prestação dos cuidados.
O pensamento Lean ou produção enxuta pode acrescentar conhecimento aos processos de produção para torná-los modelos de negócio sustentáveis. Até o final da década de 1990, esse modelo foi aplicado principalmente dentro da área de manufatura. No entanto, os conceitos da produção enxuta podem ser empregados em qualquer setor produtivo, inclusive nos de produção de serviços, como os de saúde, visto que permite alcançar altos níveis de qualidade, baixos custos e prazos de entrega adequados. As organizações usam princípios, práticas e ferramentas Lean para gerar valor aos seus clientes, ou seja, bens e serviços com uma qualidade melhor com menos defeitos. Baseada nos métodos da Toyota, o pensamento Lean leva a melhores resultados com menos esforço, espaço, dinheiro e tempo, em comparação com o sistema tradicional de produção em massa(5).

O pensamento Lean agrega alguns princípios que devem ser considerados aos processos das empresas, que são: resolver o problema do consumidor completamente, assegurando que todos os serviços funcionem juntos; não desperdiçar o tempo e nem o esforço do consumidor; prover exatamente o que o consumidor quer, onde ele quer e quando ele quer ${ }^{(6)}$.

Na saúde, são prestados e consumidos serviços, ou seja, cuidados que visam ao restabelecimento da saúde do ser humano como produto final. No processo de doação de órgãos, o objetivo dos serviços prestados passa a ser a proteção e a perfusão dos órgãos especificamente e a prioridade é garantir o melhor suporte fisiológico possível para potencializar o sucesso dos órgãos transplantados ${ }^{(7)}$.

Uma das características dos serviços é a sua variabilidade, já que dependem de quem os executa e onde são processados. Isso dificulta o controle de qualidade, exigindo muito investimento em treinamento/capacitação e padronização ${ }^{(5)}$. Tratando-se do processo de doação de órgãos, dado o grau de complexidade que este envolve, a equipe multiprofissional deve ser capaz de suprir as necessidades do potencial doador, dispondo de conhecimentos atualizados e realizando uma atuação rápida e segura.

No entanto, faz-se necessário ressaltar que existe uma desproporção cada vez maior no número de pacientes em lista que aguardam por um órgão, relativamente à disponibilidade. Há alguns fatores limitantes nesse processo, entre os quais se destaca a falta de notificação de pacientes com diagnóstico de Morte Encefálica (ME) às Centrais de Notificação, Captação e Distribuição de Órgãos; a falta de capacitação dos profissionais de saúde quanto ao processo de doação-transplante por meio da educação continuada, bem como a recusa familiar ${ }^{(1)}$.

No intuito de aprimorar e minimizar essas desproporções no processo de doação de órgãos surgiram algumas 
inquietações: como podemos melhorar o cuidado ao paciente potencial doador de órgãos que esteja em morte encefálica e consequentemente ajudar na diminuição da fila de espera por transplante? Os princípios do pensamento Lean podem possibilitar melhoria no processo de doação de órgãos?

Neste sentido, objetivou-se apresentar um modelo teórico de organização do cuidado ao paciente em morte encefálica e o processo de doação de órgãos balizado pelas principais ideias do pensamento Lean visando possibilidades de melhoria desse processo.

\section{Processo de Doação de Órgãos}

Em 1991, o Conselho Federal de Medicina (CFM) regulamentou o diagnóstico de Morte Encefálica (ME), condição para a doação de múltiplos órgãos, como a situação irreversível de todas as funções respiratórias e circulatórias ou cessação irreversível de todas as funções do cérebro, incluindo o tronco cerebral. Afirmou ainda que a $\mathrm{ME}$ deve ser consequência de processo irreversível e de causa conhecida ${ }^{(8)}$.

A identificação de pacientes em ME ocorre principalmente em UTI ou em Pronto Socorro (PS). Nesses serviços, geralmente se encontram pacientes com lesões neurológicas agudas graves, tais como hemorragia intracraniana, traumatismo cranioencefálico e lesão isquêmica, que frequentemente evoluem para $\mathrm{ME}^{(9)}$.

A detecção da ME é composta por duas etapas, o diagnóstico clínico e a realização de exame gráfico complementar. 0 primeiro deve ser realizado com intervalo de tempo conforme faixa etária do potencial doador: a) de sete dias a dois meses incompletos, repetir exame a cada 48 horas; b) de dois meses a um ano incompleto, repetir a cada 24 horas; c) de um ano a dois anos incompletos, repetir a cada 12 horas e acima de dois anos, repetir o exame com um intervalo de 6 horas $^{(8)}$. É importante enfatizar que os exames clínicos devem ser realizados por profissionais médicos diferentes, que não poderão ser integrantes da equipe de remoção e transplante, e que um dos exames deverá ser realizado por um médico neurologista.

A etapa seguinte envolve a realização de exames específicos para morte encefálica, que incluem testes motores, avaliação das respostas pupilares, avaliação do reflexo oculocefálico (fenômeno dos olhos de boneca), avaliação do reflexo oculovestibular (teste calórico com água gelada), avaliação dos reflexos corneal, de tosse e de náusea e teste da apnéia. Os exames comprobatórios de $M E$, incluem angiografia cerebral completa (para verificar a ausência de fluxo sanguíneo cerebral), angiografia cerebral radioisotópica, eletroencefalograma, Doppler transcraniano, tomografia computadorizada com contraste ou xenônio, SPECT (tomografia por emissão de fóton único para estudar os neurônios pré e pós-sináp- ticos), entre outros. Os dados clínicos e complementares observados deverão ser registrados no termo de declaração de morte encefálica ${ }^{(2,8,10)}$.

Após a constatação da morte encefálica, descartadas as contra indicações clínicas que representam riscos aos receptores dos órgãos, o paciente é considerado potencial doador de órgãos. É importante destacar que para existir o processo de doação de órgãos é necessária a confirmação do diagnóstico do paciente com ME e a notificação do potencial doador.

Após a detecção do paciente em ME é preciso realizar a manutenção do potencial doador com o objetivo é otimizar a perfusão tecidual, assegurando a viabilidade dos órgãos. Nessa etapa, é recomendado o monitoramento cardíaco contínuo; da saturação de oxigênio; da pressão arterial; da pressão venosa central; do equilíbrio hidroeletrolítico e ácido base; do débito urinário e da temperatura corporal ${ }^{(1)}$.

Ressalta-se a importância de conduzir adequadamente o potencial doador com o mesmo empenho e dedicação que qualquer outro paciente da UTI, pois este paciente não deve ser visto como um ser morto que não necessita de cuidados. Esse ser humano não deve deixar de ser singular e transformar-se em um objeto ${ }^{(11)}$, uma vez que um único potencial doador em boas condições poderá beneficiar através do transplante, mais de dez pacientes ${ }^{(12)}$. Para tanto, ressalta-se que ele deve ser cuidado como um ser que está/esteve inserido em um contexto social, familiar e cultural.

Com a confirmação do diagnóstico de $\mathrm{ME}$, a família deve ser comunicada pelo médico responsável da irreversibilidade do quadro clínico do paciente. Nesse momento, se o hospital tiver mais de 80 leitos, os profissionais que atuam na UTI ou PS comunicam-se com a Comissão Intra-hospitalar de Doação de Órgãos e Tecidos para Transplantes (CIHDOTT), que se articula com a Central de Notificação, Captação e Distribuição de Órgãos do Estado ou Distrito Federal (CNCDO), notificando a presença de um potencial doador. Se o número de leitos for inferior, a comunicação deve ser diretamente com a $\mathrm{CNCDO}^{(9,13)}$. É importante destacar que essa notificação é compulsória, independe do desejo familiar de doação ou da condição clínica do potencial doador de se converter em doador efetivo.

A CNCDO encaminhará um profissional de saúde para realizar a entrevista sobre a doação de órgãos e tecidos com o familiar. Caso a família seja favorável a doação, deverá assinar o Termo de Consentimento, o que é solicitado para o familiar e duas testemunhas. Nesse processo, a família pode decidir quais órgãos serão disponibilizados para doação.

A seguir, apresenta-se na Figura 1 a visualização do processo de doação de órgãos: 


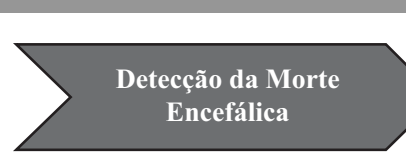

- 02 Exames clíniconeurológicos

- 01 exame gráfico complementar

- Busca identificar o potencial doador de órgãos
Avaliação do potencial doador
Manutenção do potencial doador
- Avaliação clínica e

laboratorial

- História clínica; sorologias para afastar moléstias infecciosas; viabilidade dos órgãos; teste de compatibilidade com possíveis receptores;

- Busca considerar a inexistência de contra-indicações línicas e laboratoriais no intuito de obter um enxerto de qualidade
- Estabilidade hemodinâmica - Busca otimizar a perfusão tecidual, assegurando a viabilidade dos órgãos
- Entrevista familiar

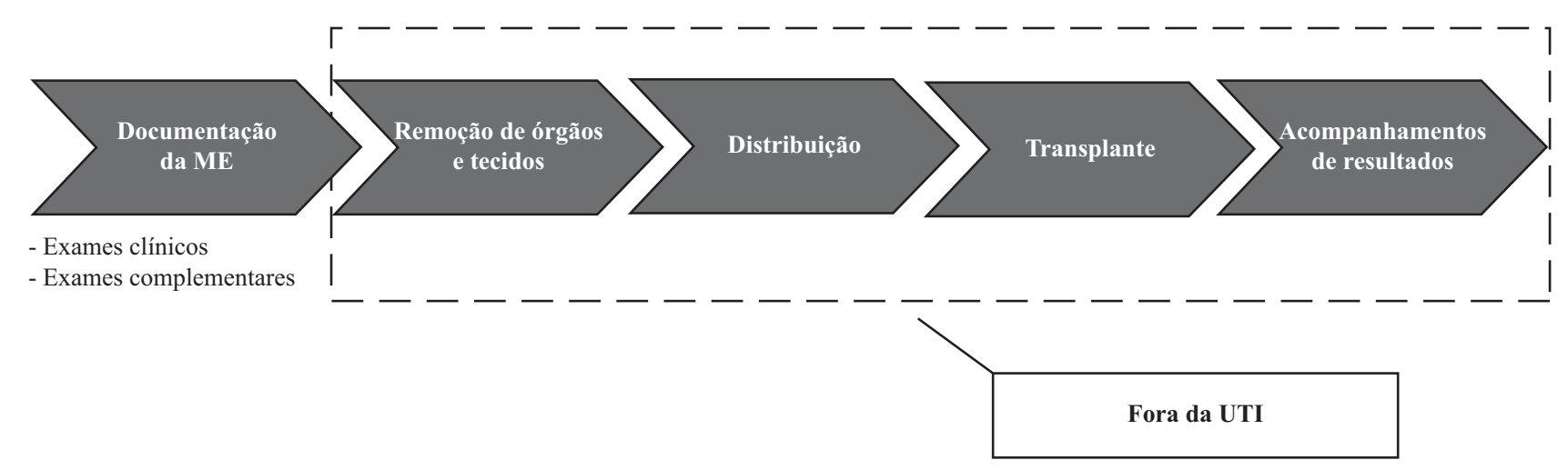

Figura 1 - Visualização do processo de doação de órgãos

No processo de doação de órgãos, existem múltiplos entraves que acabam contribuindo para o aumento do número de pacientes em lista de espera por um órgão. Entre eles, destaca-se o desconhecimento do conceito de morte encefálica por parte dos familiares e até mesmo de alguns profissionais de saúde; falta de credibilidade dos benefícios reais da doação e transplantes de órgãos; dificuldades logísticas para a manutenção do potencial doador; parada cardíaca irreversível dos potenciais doadores durante o processo de doação-transplante; contra indicação médica dos potenciais doadores; não reconhecimento ou atraso na determinação da morte encefálica, além da recusa familiar ${ }^{(1,14)}$.

\section{Relacionando algumas ideias do pensamento Lean ou produção enxuta com o processo de doação de órgãos}

O termo Lean ou mais conhecido como Lean Thinking (Mentalidade Enxuta, em português) consiste na procura pela maximização do valor através da eliminação de desperdícios por meio da prática de melhorias contínuas. Assim sendo, pode-se dizer que Lean é uma espécie de ferramenta cuja filosofia gerencial é inspirada nas práticas e resultados do Sistema Toyota de Produção ${ }^{(6,15-16)}$.

A produção enxuta é um conjunto integrado de atividades desenhado para obter uma produção de alto volume usando um mínimo de estoques de matéria primas, estoques em processo e produtos acabados. As peças chegam à próxima estação de trabalho na hora certa (just-in-time), são completadas e passam rapidamente pela operação.

A produção enxuta é uma prática para melhorar a produção por meio de ciclos de planejamentos, com habilidade dos gerentes para criar um ambiente propício para o sucesso da implementação(16-17). De modo bem simples, a produção enxuta é uma forma de se produzir mais com cada vez menos (menos esforço humano, menos equipamento, menos tempo e menos espaço) e, ao mesmo tempo, oferecendo aos clientes cada vez mais aquilo que eles desejam ${ }^{(18)}$.

A abordagem enxuta está baseada em uma série de princípios que norteiam as operações de uma organização na busca de maior qualidade, aliada à maior eficiência, o que tem trazido excelentes resultados em termos de excelência operacional e lucratividade nos diversos setores em que tem sido aplicada, seja na indústria de computadores, automobilística e siderúrgica. Alguns estudos têm empregado o Pensamento Lean nos serviços de saúde ${ }^{(5,17,19)}$.

No serviço de saúde, os pacientes esperam e /ou exigem dos profissionais um atendimento cada vez melhor e com mais qualidade e resolutividade, e para isso é necessário maior investimento no treinamento/capacitação em serviço. As instituições de saúde devem olhar para suas operações de forma que seus processos gerem valor para o cliente/usuário sob forma de um produto de qualidade, atendendo as expectativas dos pacientes, familiares, governo e sociedade. 
O produto é o resultado de um sistema de produção que será oferecido aos consumidores que pode ser um bem ou um serviço. Na área da saúde, o produto é um serviço, na Enfermagem, mais especificamente, o produto é o cuidado. Um serviço é caracterizado por ser um trabalho executado por uma pessoa em bene- fício da outra; intangível; imaterial e que não pode ser estocado(20).

A partir do exposto, esboça-se a seguir um quadro que relaciona algumas ideias do pensamento Lean ao processo de doação de órgãos (Quadro 1).

Quadro 1 - Relacionando algumas ideias do pensamento Lean ao processo de doação de órgãos

\begin{tabular}{|c|c|c|}
\hline Ideias Lean & Significado Lean & Significado no processo de doação de órgãos \\
\hline Manutenção & $\begin{array}{l}\text { A empresa deve prestar um serviço } \\
\text { confiável e de qualidade ao seu cliente. } \\
\text { Para isso a empresa deve investir em } \\
\text { manutenção, principalmente na pre- } \\
\text { ventiva, no intuito de sempre manter } \\
\text { a máquina apta a desempenhar as suas } \\
\text { funções sem falhas. No pensamento } \\
\text { Lean essa manutenção preventiva é } \\
\text { compartilhada entre os operários, não } \\
\text { existindo apenas uma única pessoa para } \\
\text { execução dessa tarefa. }\end{array}$ & $\begin{array}{l}\text { É necessário que se tenha nas instalações dos hospitais equipamentos confiáveis } \\
\text { tais como monitores multiparamétricos, respiradores artificiais, bombas de in- } \\
\text { fusão, camas leitos, dentre outros para prestarmos cuidado de qualidade ao poten- } \\
\text { cial doador de órgãos. Na saúde, a manutenção preventiva é imprescindível, pois } \\
\text { a detecção de um defeito no momento em que estamos utilizando o equipamento } \\
\text { pode até mesmo culminar com a morte do paciente. Acredita-se que essa manuten- } \\
\text { ção preventiva possa ser compartilhada no âmbito da saúde, não ficando apenas a } \\
\text { cargo do serviço de manutenção do hospital, mas também dos funcionários que } \\
\text { utilizam esses equipamentos. }\end{array}$ \\
\hline Setup & $\begin{array}{l}\text { O tempo de setup é o período que uma } \\
\text { máquina fica parada, interrompendo a } \\
\text { produção, afim de que os equipamen- } \\
\text { tos da manufatura sejam ajustados. É a } \\
\text { preparação da máquina para a próxima } \\
\text { etapa ou nova tarefa. O tempo de setup } \\
\text { desejado, ou seja, de máquina parada é } \\
\text { zero, para minimizar os custos da em- } \\
\text { presa e os tempos inúteis. }\end{array}$ & $\begin{array}{l}\text { Quando se relaciona tempo de setup ao setor saúde e mais precisamente ao proces- } \\
\text { so de doação de órgãos deve-se pensar em minimizar os tempos inúteis. Pode-se } \\
\text { imaginar a situação de levar o paciente em suspeita de morte encefálica para reali- } \\
\text { zar o exame complementar de imagem para diagnosticar a ME. Nesse momento, é } \\
\text { necessário que os equipamentos estejam disponíveis e confiáveis para que não haja } \\
\text { perda de tempo e nem danos as condições do paciente. Um exemplo disso pode } \\
\text { ser um respirador artificial portátil que não esteja funcionando adequadamente. } \\
\text { Além de comprometer as condições do paciente, ocasiona tempo inútil. Situação } \\
\text { semelhante é a espera do paciente em ME para realização da angiografia cerebral. } \\
\text { Essa demora, além de gerar a perda de tempo e danos as condições do paciente, } \\
\text { pode acarretar em aumento nos custos hospitalares. Dessa forma é importante a } \\
\text { minimização do tempo de setup na saúde. }\end{array}$ \\
\hline $\begin{array}{l}\text { Sistema de infor- } \\
\text { mação }\end{array}$ & $\begin{array}{l}\text { Elaborar um sistema de informação } \\
\text { prontamente disponível, confiável e de } \\
\text { fácil interpretação. }\end{array}$ & $\begin{array}{l}\text { A partir do momento em que se identifica um potencial doador, seja na UTI ou no } \\
\text { PS, os profissionais devem ter clareza dos protocolos, das rotinas e dos fluxos, pois } \\
\text { eles devem agir com competência técnica, científica, humanística e de forma in- } \\
\text { tegrada/articulada entre si. No momento em que há a suspeita da morte encefálica } \\
\text { de um paciente deve ser iniciado o protocolo de ME. São necessários dois exames } \\
\text { clínicos neurológicos, sendo que um deve ser realizado por um neurologista e o } \\
\text { outro por um médico intensivista. Depois da realização do exame neurológico, } \\
\text { e se este for positivo para ME, o enfermeiro deve comunicar a Comissão Intra- } \\
\text { hospitalar de Doação de Órgãos e Tecidos para Transplantes (CIHDOTT). Esse } \\
\text { sistema de informação deve está bem definido para os profissionais no intuito de } \\
\text { facilitar o processo de doação, evitando que haja perda de tempo e informações } \\
\text { desencontradas ou erradas. }\end{array}$ \\
\hline $\begin{array}{l}\text { Treinamento/capaci- } \\
\text { tação Multifunciona- } \\
\text { lidade }\end{array}$ & $\begin{array}{l}\text { Treinar/capacitar os funcionários para } \\
\text { que eles sejam polivalentes e tenham } \\
\text { uma visão sistêmica da organização e } \\
\text { dos seus processos para que dominem } \\
\text { diversas funções, }\end{array}$ & $\begin{array}{l}\text { O processo de doação é complexo e relativamente recente na área da saúde. Por- } \\
\text { tanto, requer dos profissionais atualização e capacitação/treinamento constantes } \\
\text { em relação aos novos conhecimentos produzidos sobre esse processo, a fim de ga- } \\
\text { rantir maior agilidade e qualidade no atendimento tanto ao doador quanto ao recep- } \\
\text { tor do órgão. A multifuncionalidade do profissional na área da saúde é um pouco } \\
\text { mais difícil, pois o atendimento ao potencial doador é multiprofissional, e para que } \\
\text { o cuidado a esse paciente seja de qualidade é necessário que cada profissional seja } \\
\text { capaz de agir prontamente com competência e rigor técnico-científico na sua esfera } \\
\text { de atuação. O enfermeiro, dentro da equipe multiprofissional, gerencia o cuidado } \\
\text { ao paciente em morte encefálica, e desempenha ações importantes na captação } \\
\text { de órgãos, atuando principalmente na identificação de doadores, manutenção he- } \\
\text { modinâmica, na comunicação com os centros de transplantes e com familiares do } \\
\text { doador com a finalidade de viabilizar o processo de doação de órgãos. Também é } \\
\text { importante que as questões éticas e de relaçõ̃es humanas envolvidas na doação de } \\
\text { órgãos sejam contempladas nessas capacitações. }\end{array}$ \\
\hline $\begin{array}{l}\text { Máquina multifun- } \\
\text { cional }\end{array}$ & $\begin{array}{l}\text { São máquinas capazes de desempenhar } \\
\text { várias funções }\end{array}$ & $\begin{array}{l}\text { No processo de cuidado ao paciente em morte encefálica potencial doador de órgãos } \\
\text { está envolvido várias máquinas multifuncionais que são utilizadas para facilitar e } \\
\text { monitorar o cuidado mais criteriosamente. O monitor cardíaco multiparamétrico é } \\
\text { um equipamento que desempenha várias funções. Determina a frequência cardíaca, } \\
\text { frequência respiratória, pressão arterial; temperatura dentre outros parâmetros que } \\
\text { auxiliam os profissionais de saúde a preservar e manter o doador e o receptor dos } \\
\text { órgãos. Mesmo com todo esse aparato tecnológico, o acolhimento e a humanização } \\
\text { do cuidado ao paciente em ME e a sua família são indispensáveis. }\end{array}$ \\
\hline $\begin{array}{l}\text { Automação/Au- } \\
\text { tomática }\end{array}$ & $\begin{array}{l}\text { As máquinas interpretam as situações e } \\
\text { adaptam-se automaticamente }\end{array}$ & $\begin{array}{l}\text { Na saúde, pode-se imaginar um cenário no futuro em que máquinas serão pro- } \\
\text { gramadas para identificar uma situação ou problema específico e imediatamente } \\
\text { efetuar a correção. Pode-se imaginar um monitor multiparamétrico identificando } \\
\text { uma instabilidade hemodinâmica do paciente e automaticamente fazer o ajuste } \\
\text { da medicação. Mesmo que essas máquinas altamente qualificadas sejam criadas, } \\
\text { acredita-se que jamais substituirá o cuidado humanizado ao paciente. }\end{array}$ \\
\hline
\end{tabular}


Com base nas relações apresentadas acima, elaborou-se um modelo teórico de organização do cuidado ao paciente em morte encefálica e o processo de doação de órgãos, balizado nas principais ideias do pensamento Lean (Figura 2).

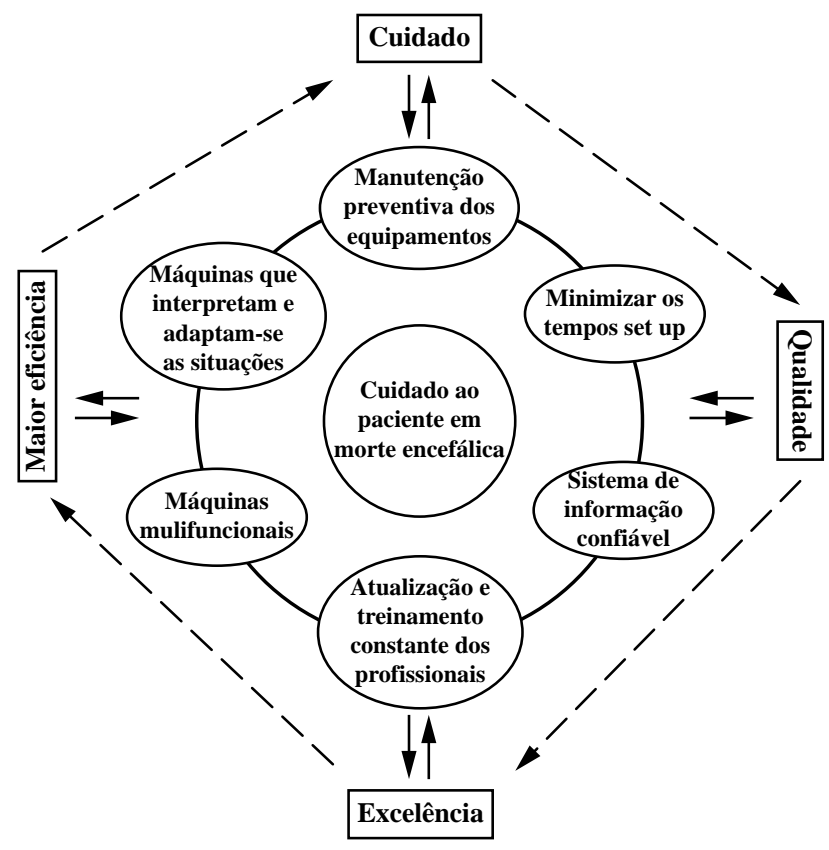

Figura 2 - Modelo teórico de organização do cuidado ao paciente em morte encefálica no processo de doação de órgãos ancorado nas principais ideias do pensamento

O conhecimento do processo e a execução adequada de suas etapas possibilitam a obtenção de órgãos e tecidos com mais segurança e qualidade, potencializando o diagnóstico de morte encefálica, a captação do órgão doado, o acondicionamento, o transporte até o local do transplante do órgão no receptor. Essa melhoria advém de um planejamento e organização do cuidado a esse paciente uma vez que será realizada a manutenção preventiva dos equipamentos; o tempo de setup será mínimo; o sistema de informação será efetivo; os profissionais estarão atualizados e devidamente capacitados para realizar o cuidado. Dessa forma, pode-se alcançar maior eficiência, qualidade e excelência no cuidar, garantindo melhoria contínua desse processo e beneficiando tanto os profissionais de saúde quanto familiares dos doadores e os receptores.

\section{REFERÊNCIAS}

1. Associação Brasileira de Transplante de Órgãos (ABTO). Diretrizes Básicas para captação e retirada de múltiplos órgãos e tecidos da Associação Brasileira de Transplante de Órgãos. São Paulo: ABTO; 2009.
Cada um destes conceitos pode induzir a um esforço específico de melhoria. Ações coletivas e interativas entre os integrantes das equipes da saúde, aliadas a conhecimentos de gestão operacional, serão capazes de interpretar e associar os conceitos Lean e colocá-los a favor da eficiência do sistema de produção em saúde, neste caso, de doação de órgãos.

\section{CONCLUSÃO}

O desenvolvimento desse estudo permitiu uma reflexão e uma melhor compreensão sobre o processo de doação de órgãos e as principais ideias do pensamento Lean. A partir de um breve resgate foi possível contextualizar o processo de doação com esse novo pensamento que tem sido empregado na área da saúde cuja finalidade é atingir melhores resultados com menor esforço. E para isso utilizou-se as principais ideias do pensamento Lean: manutenção; setup; sistema de informação; treinamento/capacitação/multifuncionalidade; máquina multifuncional; automação/automática.

Transpor as principais ideias do pensamento Lean para processo de doação de órgãos foi um desafio, uma vez que esse modelo desenvolveu-se principalmente para área da manufatura. Porém, a partir dessa reflexão teórica foi possível aplicá-lo em diferentes níveis ao processo de doação de órgãos. Destaca-se que o pensamento Lean pode tornar mais eficaz e eficiente o processo de doação de órgãos, contribuindo para sua melhoria, a partir da sistematização das informações, da capacitação dos profissionais, garantindo um cuidado de qualidade ao paciente, sem engessar as condutas, mas fornecendo informações de como agir diante das situações que podem ocorrer. Nesse sentido, este modelo teórico pode trazer contribuições, devendo-se considerar os aspectos relativos à humanização, comunicação, vínculo e ética, os quais são indispensáveis na relação com os pacientes e familiares envolvidos no processo de doação de órgãos.

Acredita-se que este trabalho possa incentivar novas pesquisas acadêmicas na área da saúde utilizando a produção enxuta, tendo em vista que essa área, assim como todos os sistemas de produção, deve estar aberto a meIhorias contínuas. No âmbito da prática assistencial em saúde, essas ideias podem contribuir para a melhoria do processo de doação de órgãos; as etapas desse processo devem ser tomadas em detalhe e soluções específicas que podem ser geradas sob o abrigo destes conceitos mais amplos para potencializar melhorias na atuação da equipe multiprofissional.
2. Mattia $A L$, Rocha $A M$, Freitas Filho JPA, Barbosa $M H$, Rodrigues MB, Oliveira MG. Análise das dificuldades no processo de doação de órgãos: uma revisão integrativa da literatura. Rev Biocthikos. 2010;(1)4:66-74. 
3. Flodén A, Forsberg A. A phenomenografic study of ICU-nurses's perceptions of and attitudes to organ donation and care of potential donors. Intensive Crit Care Nurs. 2009;25(6):306-13.

4. Cinque VM, Bianchi ERF. Stressor experienced by family members in the process of organ and tissue donation for transplant. Rev Esc Enferm USP [Internet]. 2010 [cited 2011 Nov 24];44(4): 996-1002. Available from: http://www.scielo. $\mathrm{br} / \mathrm{pdf} /$ reeusp/v44n4/en_20.pdf

5. Selau LPR, Pedó MG, Senff DS, Saurin TA. Produção enxuta no setor de serviços: caso do Hospital de Clínicas de Porto Alegre - HCPA. Rev Gestão Indust. 2009;5(1):122-40.

6. Pinto JP. Pensamento Lean: a filosofia das organizações vencedoras. Lisboa: Lidel; 2009.

7. Rech TH, Rodrigues Filho EM. Manuseio do potencial doador de múltiplos órgãos. Rev Bras Ter Intensiva. 2007;19(2):197-204.

8. Conselho Federal de Medicina. Resolução n. 1.480/97, de 08 de agosto de 1997. Estabelece os critérios para caracterização de morte encefálica [Internet]. Brasília; 1997 [citado 2010 dez. 01]. Disponível em: http://www.hc.unicamp.br/ servicos/cco/formularios/07_form.pdf

9. Domingos GR, Boer LA, Possami FP. Doação e captação de órgãos de pacientes com morte encefálica. Enferm Bras. 2010;9(4):206-12.

10. Souza SS. Estratégias de enfrentamento da enfermagem no cuidado ao potencial doador de órgãos [dissertação]. Florianópolis: Programa de Pós-Graduação em Enfermagem, Universidade Federal de Santa Catarina; 2010.

11. Nascimento ERP, Trentini M. O cuidado de enfermagem na Unidade de Terapia Intensiva (UTI): teoria humanística de Paterson e Zderad. Rev Latino Am Enferm. 2004;12(2):250-7.

12. Araújo $S$, Cintra EA, Bachega EB. Manutenção do potencial doador de órgãos. In: Cintra EA, Nishide VM, Nunes WA, organizadores. Assistência de enfermagem ao paciente gravemente enfermo. São Paulo: Atheneu; 2005. p. 443-56.
13. Brasil. Portaria n. 1.752/GM, 23 de setembro de 2005. Determina a constituição de Comissão Intra-hospitalar de Doação de Órgãos e Tecidos para Transplantes em todos os hospitais públicos, privados e filantrópicos com mais de 80 leitos [Internet]. Brasília; 2005 [citado 2011 fev. 02]. Disponível em: http://www.saude.mg.gov.br/atos_normativos/ legislacao-sanitaria/estabelecimentos-de-saude/transplantes-implantes/Portaria_1752.pdf/view

14. Mendonça AS, Castro DC, Brasileiro ME. Assistência de enfermagem na manutenção do potencial doador de órgãos. Rev Eletr Enferm Centro Estudos Enferm Nutrição [Internet]. 2010 [citado 2010 dez. 15];1(1):1-15. Disponível em: http://www.ceen.com.br/revistaeletronica

15. Waring JJ, Bishop S. Lean healthcare: rhetoric, ritual and resistance. Soc Sci Med. 2010;71(7):1332-40.

16. Jacobs FR, Chase RB. Administração da produção e operações: o essencial. Porto Alegre: Bookman; 2009.

17. Lima AC. Práticas do pensamento enxuto em ambientes administrativos: aplicação na divisão de suprimentos de um hospital público [tese]. Campinas: Faculdade de Engenharia Mecânica, Universidade Estadual de Campinas; 2007.

18. Womack JP, Jones DT. A mentalidade enxuta nas empresas Lean Thinking: elimine o desperdício e crie riqueza. Rio de Janeiro: Elsevier; 2004.

19. Moccellin F, Mussetti MA. Lean thiking: aplicação em um ambulatório hospitalar. In: Anais do 11 Simpósio da Engenharia de Produção; 2004 nov. 8-10; São Paulo, Brasil. São Paulo: UNESP; 2004. p. 1-8.

20. Fitzsimmons JA, Fitzsimmons MJ. Admistração de serviços: operações, estratégia e tecnologia da informação. Porto Alegre: Bookman; 2005. 